\title{
Associations Between Psychiatric Disorders and Enuresis in Taiwanese Children: A National Population-Based Study
}

This article was published in the following Dove Press journal:

Clinical Epidemiology

\author{
Hsin-Lin Tsai ${ }^{1,2}$ \\ Jei-Wen Chang ${ }^{2,3}$ \\ Mu-Hong Chen (iD) ${ }^{4,5}$ \\ Mei-Jy Jeng $\mathbb{D D}^{3,6}$ \\ Ling-Yu Yang (D) $^{2,7}$ \\ Keh-Gong $W_{u^{2,3}}$
}

'Division of Pediatric Surgery,

Department of Surgery, Taipei Veterans

General Hospital, Taipei, Taiwan; ${ }^{2}$ Faculty

of Medicine, School of Medicine, National

Yang-Ming University, Taipei, Taiwan;

${ }^{3}$ Department of Pediatrics, Taipei

Veterans General Hospital, Taipei,

Taiwan; ${ }^{4}$ Department of Psychiatry, Taipei

Veterans General Hospital, Taipei,

Taiwan; ${ }^{5}$ Department of Psychiatry,

School of Medicine, National Yang-Ming

University, Taipei, Taiwan; ${ }^{6}$ Institute of

Emergency and Critical Care Medicine,

National Yang-Ming University, Taipei,

Taiwan; ${ }^{7}$ Department of Education, Taipei

Veterans General Hospital, Taipei, Taiwan
Background: Psychiatric disorders such as attention-deficit/hyperactivity disorder may negatively impact drug compliance and the prognosis of enuresis. However, existing studies regarding associations between lifetime psychiatric disorders and childhood enuresis are primarily from Western countries, and studies from Taiwan are lacking.

Methods: We conducted a population-based retrospective cohort analysis using the Taiwan Longitudinal Health Insurance Database 2010. A total of 1,146 children with enuresis (ICD9-CM code: 307.6) and 4,584 randomly selected sex- and age-matched controls were identified between January 1, 1997 and December 31, 2011. Logistic regression was used to estimate the odds ratios (ORs) and 95\% confidence intervals (CIs) for the development of psychiatric disorders in the children with enuresis.

Results: Enuresis was more common in the younger children, and the rate was significantly higher in boys $(58.7 \%)$ than in girls $(41.3 \%)$. A total of 171 patients $(14.9 \%)$ in the enuresis group had at least one psychiatric diagnosis vs $259(5.7 \%)$ in the control group $(\mathrm{p}<0.001)$. Multivariate analysis showed that the presence of enuresis increased the odds of developing major depressive/dysthymic disorder ( $\mathrm{OR}=2.841,95 \% \mathrm{CI}: 1.619,4.987)$, attention-deficit /hyperactivity disorder $(\mathrm{OR}=3.156,95 \% \mathrm{CI}: 2.446,4.073)$, autism spectrum disorder $(\mathrm{OR}=2.468,95 \% \mathrm{CI}: 1.264,4.822)$, anxiety disorders (OR=3.113, 95\% CI: 2.063, 4.699), intelligence disability $(\mathrm{OR}=3.989,95 \% \mathrm{CI}: 2.476,6.426)$, disruptive behavior disorders $(\mathrm{OR}=3.749,95 \%$ CI: 1.756, 8.004), and tic disorder (OR=2.660, 95\% CI: 1.642, 4.308).

Conclusion: Children with enuresis are likely to have psychiatric disorders, and physicians should consider this during their evaluation.

Keywords: psychiatric disorder, enuresis, attention-deficit/hyperactivity disorder, children

\section{Introduction}

Enuresis is defined as involuntary voiding of urine into clothes or bed in children aged 5 years old or older. On the basis of the time of occurrence, enuresis can be further divided into three subtypes, including diurnal enuresis, nocturnal enuresis and combined according to the Diagnostic and Statistical Manual of Mental Disorders. ${ }^{1}$ In contrast, the International Children's Continence Society restricts enuresis to intermittent wetting that occurs at night, while incontinence that occurs when awake is termed daytime incontinence. ${ }^{2}$ Enuresis is a common problem among children and adolescents, and recent epidemiologic studies have reported an overall prevalence ranging from $3.9 \%$ to $18.9 \%$ depending on age, race/ethnicity, and definition of enuresis used. ${ }^{3-5}$ Primary enuresis often resolves over time with
Correspondence: Jei-Wen Chang Department of Pediatrics, Taipei Veterans General Hospital, No. 20I, Sec.2, Shipai

Road, Beitou District, Taipei City II2I7,

Taiwan, Republic of China

Tel +886-2-2875-7576

Fax +886-2-2873-9019

Email jwchang@vghtpe.gov.tw 
a spontaneous annual remission rate of approximately $15 \%$. In the majority of cases, parents consider enuresis to be a self-limiting problem, and therefore the decision of when to seek medical advice varies. Despite its high prevalence, prior studies have reported that only $2.1 \%$ to $55 \%$ of the parents of children with nocturnal enuresis seek medical care. ${ }^{6,7}$

A number of studies have reported an association between enuresis and an increased risk of attention-deficit /hyperactivity disorder (ADHD), and $4.1 \%$ to $74.9 \%$ of subjects with enuresis have been reported to have ADHD. ${ }^{8-12}$ ADHD has also been reported to be a risk factor for persistent nocturnal enuresis after treatment. ${ }^{13}$ However, associations between other psychiatric disorders and enuresis are controversial. Ghanizadeh et al reported a higher incidence of oppositional defiant disorder (ODD) in children with ADHD and enuresis, ${ }^{14}$ and a large population-based study from the United Kingdom reported higher rates of conduct disorder (CD), major depressive/dysthymic disorder (MDD), and anxiety disorders in children with enuresis. $^{15}$ In contrast, a national study from the United States did not find any associations between CD and anxiety disorders and enuresis. ${ }^{8}$

Previous studies have reported that urbanization and racial/ethnic differences are associated with different risks of developing mental disorders. ${ }^{16}$ However, the existing studies regarding the occurrence of psychiatric disorders in children with enuresis are primarily from Western countries, and studies from Taiwan are lacking. In addition, the risk of comorbid psychiatric disorders in boys relative to girls with enuresis has received relatively little attention. Therefore, the aims of this study were (1) to examine the effects of urbanization on enuretic children who seek medical evaluation and treatment, (2) to determine the association between enuresis and lifetime psychiatric disorders, and (3) to examine sex differences in the association between psychiatric disorders and enuresis in Taiwanese children.

\section{Materials and Methods \\ Data Source}

The Taiwanese National Health Insurance (NHI) program was launched in 1995, and by the end of 2008 covered $99.48 \%$ of the population in Taiwan (http:/www.nhi.gov.tw). The National Health Insurance Research Database (NHIRD) contains comprehensive claims records of outpatient, inpatient, and emergency care of insured individuals including demographic data, clinical visit dates, disease diagnoses, and prescription drugs. To protect patient privacy, these data are de-identified by encrypting all personal identification information before being released for research. To ensure the accuracy of diagnostic coding in the NHIRD, the Bureau of NHI regularly randomly reviews a sample of the medical charts and claims. Fraudulent coding and overcharging by physicians and institutions are subject to severe penalties or suspensions. Data for this study were obtained from the Longitudinal Health Insurance Database 2010 (LHID 2010) provided by the National Health Research Institutes. This database is a subdataset of the NHIRD, and includes scrambled identification codes, personal information, and outpatient (ambulatory) care and inpatient care records of one million beneficiaries who were randomly selected in 2010 from the original registry of beneficiaries in the Taiwan NHI program. The NHIRD includes data on approximately 27.38 million beneficiaries of the NHI program during January 1, 2010 to December 31, 2010, and the LHID 2010 represents about 3.65\% of the total population in Taiwan. The NHI has reported that there are no significant differences in age, sex, or healthcare costs between the LHID and the whole insured population. In addition, new claims data of the cohort are released every year. This study was approved by the Institutional Review Board of Taipei Veterans General Hospital (2016-04-002AC).

\section{Inclusion and Exclusion Criteria for the Children with and Without \\ Enuresis}

We extracted the records of children between 5 and 18 years of age with a new diagnosis of enuresis (International Classification of Diseases, Ninth Revision, Clinical Modification (ICD-9-CM): 307.6) with at least two medical services either at outpatient clinics or in inpatient records from January 1, 1997 to December 31, 2011. The first date of a diagnosis of enuresis was considered to be the index date. Patients with a diagnosis of neuropathic bladder (ICD9-CM: 596.5x), neurogenic bladder due to cauda equina syndrome (ICD-9-CM: 344.61), and those with other diagnoses of urine incontinence (ICD-9-CM:788.31-788.35 and 788.37-788.39) were excluded. The control cohort was randomly selected from the LHID 2010 at a $4: 1$ ratio matched by age, sex, index year, and index month using the same exclusion criteria during the same period. Age was categorized into three groups: 5-6 years, 7-12 years, and 13-18 years. 


\section{Level of Urbanization}

In Taiwan, urbanization is divided into seven strata based on population density (people per $\mathrm{km}^{2}$ ), percentage of residents with college level or higher education, percentage of people over 65 years of age (elderly), percentage of residents who are agricultural workers, and number of physicians per 100,000 people. $^{17}$ We further classified the urbanization level as urban (levels 1-2), suburban (levels 3-4), and rural (levels 5-7).

\section{Psychiatric Disorders}

We investigated associations between enuresis and the following psychiatric disorders: MDD (ICD-9-CM: 296.2, 296.3, 300.4, 311), bipolar disorder (ICD-9-CM: 296.0, 296.1, 296.4, 296.5, 296.6, 296.7, 296.80, 296.81, 296.89), ADHD (ICD-9-CM: 314), autism spectrum disorder (ASD) (ICD-9-CM: 299), anxiety disorders (ICD-9-CM: 300.0, 300.1, 300.2, 300.5, 300.6, 300.7, 300.8, 300.9), schizophrenia (ICD-9-CM: 295), ODD (ICD-9-CM: 313.81), CD (ICD9-CM: 312), and tic disorder (ICD-9-CM: 307.2). Disruptive behavior disorders (DBD) included ODD and CD. Intelligence disability (ICD-9-CM: 317, 318, 319) was also examined. The presence of psychiatric disorders before and after the children were diagnosed with enuresis was identified.

\section{Statistical Analysis}

Continuous data were described as means and standard deviations (mean $\pm \mathrm{SD}$ ), and examined using the $t$-test. Categorical data were expressed as numbers and percentages, First, we compared demographic data and psychiatric disorders between the enuresis group and non-enuresis group using Fisher's exact test or the chi-square test. We then performed univariate logistic regression analysis to assess the associations between enuresis and psychiatric disorders. Results were reported as odds ratios (ORs) and $95 \%$ confidence intervals (CIs). We further estimated the ORs of developing psychiatric disorders in the children with enuresis after adjusting for sex, age, and urbanization in multivariate logistic regression analysis. All statistical analyses were performed using SPSS version 18.0 (SPSS Inc., Chicago, IL, USA). P values of $<0.05$ were considered to indicate statistical significance.

\section{Results}

\section{Clinical Characteristics}

The demographic characteristics and lifetime psychiatric disorders of the subjects are shown in Table 1. In total,
1146 children with enuresis and 4584 control children were included in the analysis. Significantly more boys (58.7\%) had enuresis than girls $(41.3 \%)$, and the male/female ratio was 1.42:1. Enuresis was most commonly diagnosed in children aged 7 to 12 years, with the lowest rate in those aged over 12 years. Overall, $95.5 \%$ of the children were aged 5 to 12 years, and the mean age at the first visit was $8.46 \pm 2.46$ years. Most of the children lived in urban areas $(62.0 \%)$, and there were no statistically significant differences in urbanization level, age and sex (all $\mathrm{p}>0.05$ ). Significantly more children with enuresis had psychiatric disorders $(14.9 \%)$ than those without enuresis $(5.7 \%, \mathrm{p}<$ 0.001 ) (Table 1). Sixty-seven (39.2\%) of the 171 children with enuresis and psychiatric conditions had two or more psychiatric disorders. The most commonly diagnosed psychiatric disorder in the enuresis group was ADHD (112, 9.8\%), followed by anxiety disorders (41, 3.6\%). Children with MDD (OR=2.834, 95\% CI: 1.616-4.968), ADHD ( $\mathrm{OR}=3.095,95 \%$ CI: $2.405-3.983)$, ASD ( $\mathrm{OR}=2.453,95 \%$ CI: $1.258-4.781)$, anxiety disorders $(\mathrm{OR}=3.113,95 \% \mathrm{CI}$ : 2.063-4.696), ODD (OR=4.820, 95\% CI: $1.468-15.821)$, $\mathrm{CD}(\mathrm{OR}=2.811,95 \% \mathrm{CI}: 1.068-7.401), \mathrm{DBD}(\mathrm{OR}=3.745$, 95\% CI: $1.756-7.990)$, and tic disorder ( $\mathrm{OR}=2.645,95 \%$ CI: $1.636-4.276)$, as well as intelligence disability (OR=3.974, 95\% CI: 2.468-6.400), had a higher likelihood of enuresis. There was no significant difference in the age at a first diagnosis of a psychiatric disorder between the enuresis group and non-enuresis group.

\section{Association Between Enuresis and Psychiatric Disorders}

Results of the multivariate logistic regression analysis after adjusting for age, sex and level of urbanization to compare the risks of psychiatric disorders between the enuretic and non-enuretic cohorts are shown in Table 2 . The children with enuresis had greater odds of developing MDD ( $\mathrm{OR}=2.841$, 95\% CI: 1.619, 4.987), ADHD (OR=3.156, 95\% CI: 2.446, 4.073), ASD ( $\mathrm{OR}=2.468,95 \% \mathrm{CI}: 1.264,4.822)$, anxiety disorders ( $\mathrm{OR}=3.113,95 \% \mathrm{CI}: 2.063,4.699)$, intelligence disability (OR=3.989, 95\% CI: 2.476, 6.426), DBD $(\mathrm{OR}=3.749,95 \% \mathrm{CI}: 1.756,8.004)$, and tic disorder $(\mathrm{OR}=2.660,95 \%$ CI: 1.642, 4.308) compared to the children without enuresis. Moreover, the children with enuresis had a 2.968 -fold increased odds (95\% CI: $2.413,3.659)$ of having any one of the studied psychiatric disorders than those without enuresis. However, enuresis was not associated with an increased OR for bipolar disorder or schizophrenia. Data 
Table I Comparisons of Demographic Data and Psychiatric Disorders Between the Enuresis and Non-Enuresis Groups with Odds Ratios (ORs) Measured in Univariate Logistic Regression Analysis

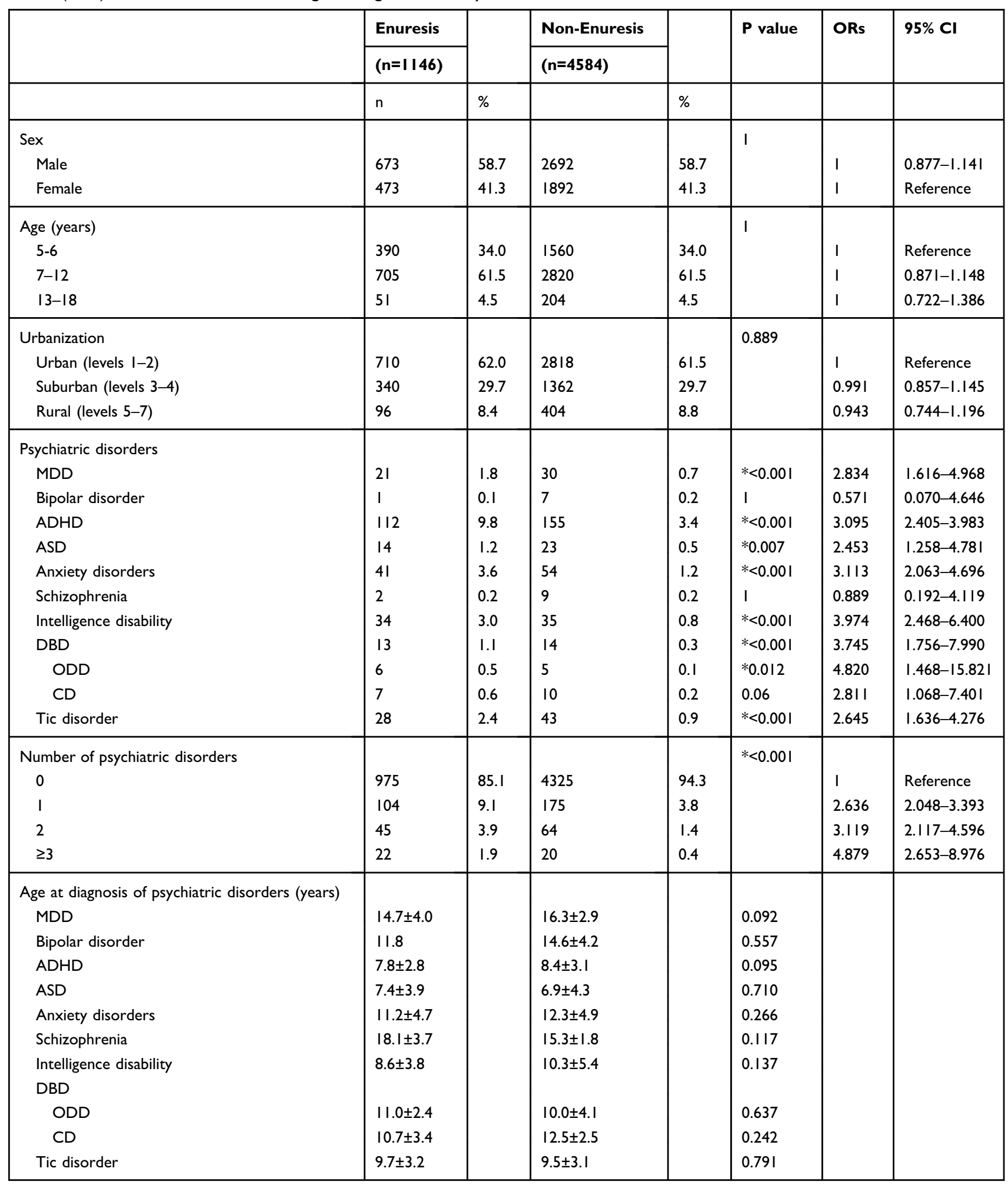

Note: *Fisher's exact test or Chi-square test $\mathrm{P}<0.05$.

regarding sex, age, and level of urbanization are not shown. both sexes, enuresis was significantly associated with MDD, Tables 3 and 4 show the associations between psychiatric ADHD, anxiety disorders, intelligence disability, DBD and disorders in the boys and girls with enuresis, respectively. For tic disorder. The OR of the patients with enuresis suffering 

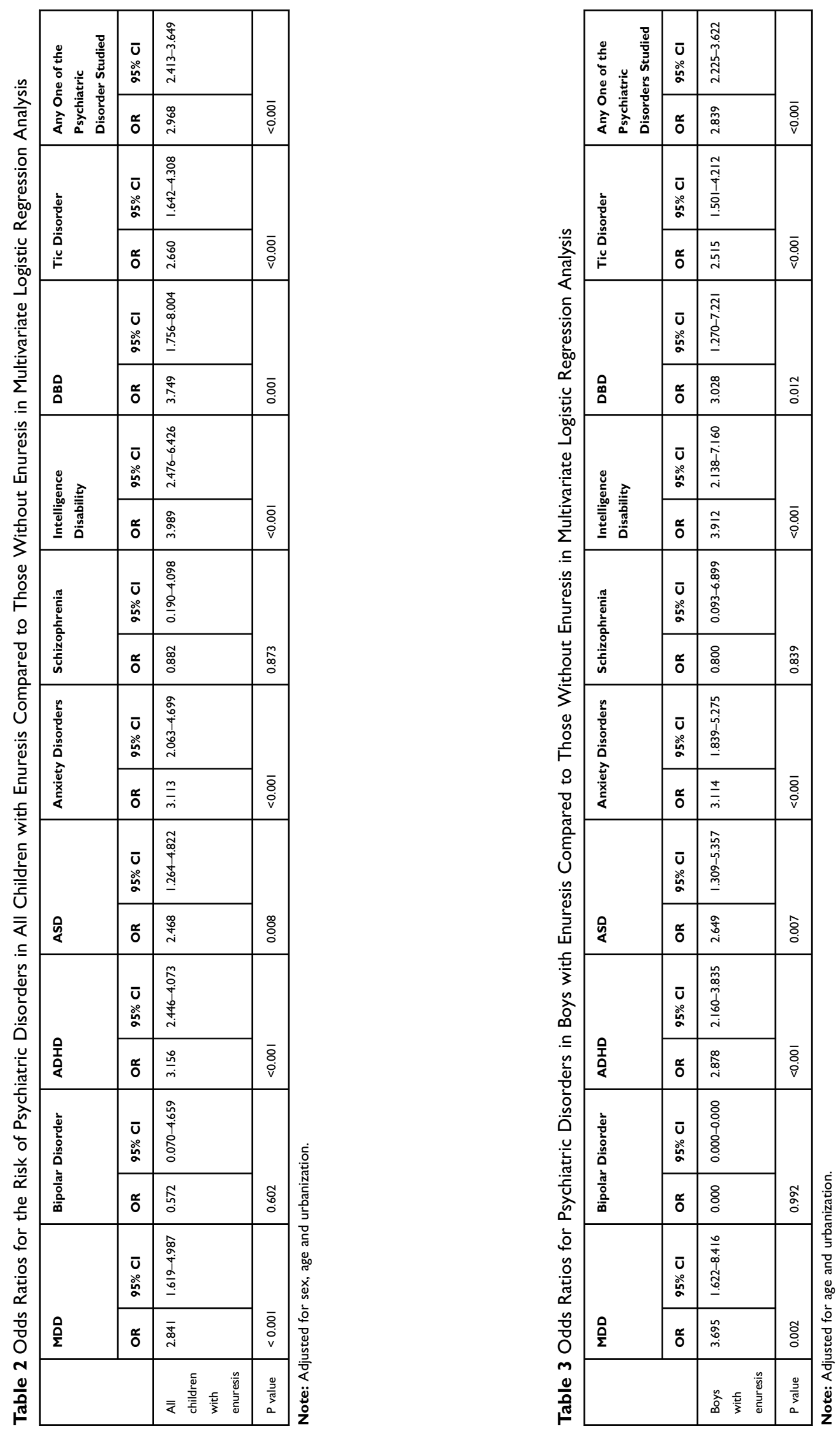


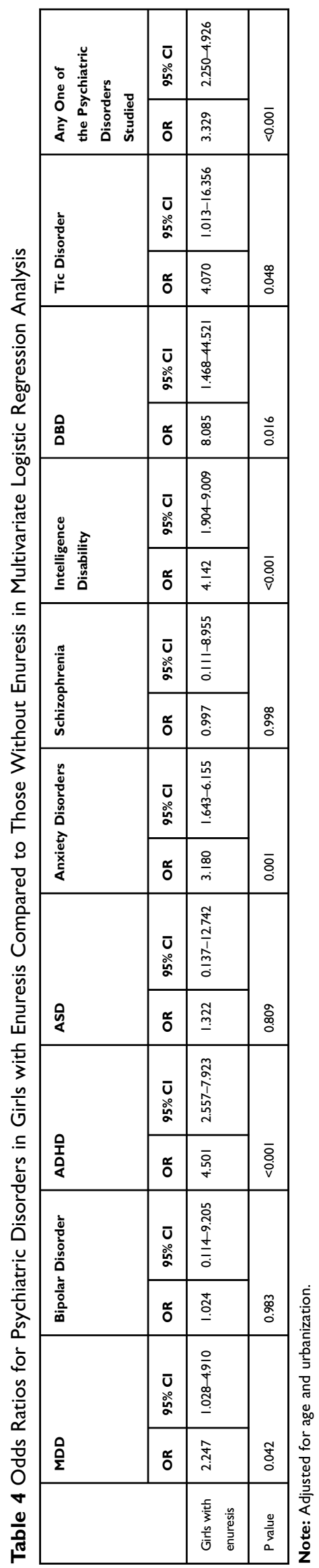

from ASD was significantly higher in the boys ( $\mathrm{OR}=2.649$; $95 \% \mathrm{CI}, 1.309,5.357)$ but not in the girls $(\mathrm{OR}=1.322 ; 95 \%$ CI, 0.137, 12.742). In sex-stratified analysis, the boys had a higher OR of developing MDD and ASD than the girls. However, the ORs of ADHD, anxiety disorders, intelligence disability, DBD disorder and tic disorder were much higher in the girls with enuresis than in the boys with enuresis.

\section{Discussion}

Enuresis is a common problem in children. Controversy with regards to the pathophysiology of enuresis has existed for many years. A higher risk of enuresis has also been reported in boys than in girls. In the current study, the boys had a 1.42-fold higher rate of enuresis than the girls, which is consistent with previous studies. ${ }^{3}$ In addition, our findings also support previous research that enuresis occurs more commonly at a younger age, and then tends to decrease with age.

Epidemiological studies have reported that children with enuresis are two to four times as likely to have behavioral problems as children without enuresis. ${ }^{18,19}$ Our results are consistent with the previous studies, in that $14.9 \%$ of the children with enuresis had psychiatric disorders, and they were 2.968 -fold more likely to have psychiatric disorders than those without enuresis. The rates of associated psychiatric disorders except ADHD in the present study were all much lower than the rate reported in a previous study. ${ }^{15}$ The high rate of co-morbidity of enuresis and ADHD (predominantly the inattentive type) has been thoroughly studied. ${ }^{8,12}$ Shreeram at al. reported that the OR of having ADHD in children with enuresis was 2.88. ${ }^{8}$ In the current study, ADHD was the most common psychiatric disorder associated with enuresis, and $9.8 \%$ of the children with enuresis were diagnosed with ADHD compared to $3.4 \%$ of those without enuresis. We also found that the children with enuresis had a 3.156-fold increased odds of having ADHD compared to those without enuresis. In our enuresis cohort, the rate of comorbidity with ADHD was similar to that reported by von Gontard et $\mathrm{al}^{20}$ but lower than that reported in a specialized tertiary care setting. ${ }^{10}$ Several studies recruiting children with ADHD reported that $12.1-32 \%$ of the children also had clinical symptoms of enuresis, ${ }^{21-23}$ which supports that enuresis may coexist with ADHD and vice versa.

In addition to ADHD, it has been demonstrated that enuretic children have higher rates of psychiatric disorders such as depressive problems, ${ }^{15} \mathrm{ODD},{ }^{15} \mathrm{CD},{ }^{15}$ obsessive- 
compulsive disorder, ${ }^{24}$ schizophrenia, ${ }^{25}$ Tourette syndrome, ${ }^{26} \mathrm{ASD},{ }^{27}$ and anxiety disorders. ${ }^{15} \mathrm{We}$ found higher odds of having MDD, ADHD, ASD, anxiety disorders, intelligence disability, DBD and tic disorder in the children with enuresis in multivariate logistic analysis. However, anxiety disorders other than $\mathrm{DBD}^{15}$ were the second most common comorbid psychiatric disorders in the current study. Males have been reported to be at a greater risk of ADHD and enuresis and also other psychiatric disorders such as ASD, intellectual disability and communication disorders, Tourette syndrome, ODD, CD, and schizophrenia, while female predominance has been observed in adolescent-onset emotional disorders such as depressive and anxiety disorders. ${ }^{28}$ We also investigated whether or not enuresis was a sex-dependent risk factor for ADHD and other psychiatric disorders. Both the boys and girls with enuresis had more psychiatric problems, but surprisingly, we found that the girls with enuresis had higher odds of developing ADHD as well as DBD, tic disorder, and intelligence disability, compared with the boys, which is in contrast to previous clinical studies. ${ }^{29}$ Consistent with previous epidemiological studies, we also found that the girls had a higher rate of anxiety disorders. This higher odds of ADHD and other psychiatric disorders in girls may be because girls are more likely to visit a healthcare provider for behavioral problems or emotional issues than boys.

The etiologies of both enuresis and ADHD are multifactorial and controversial. There are some similarities between these two disorders, and researchers have shown that both primary nocturnal enuresis and ADHD appear to be heritable, with a complex inheritance model, ${ }^{30,31}$ male predominance, and the tendency to improve with age. Although many studies have reported an association between enuresis and ADHD, whether or not there is a direct causal relationship is unknown. Previous neuropathological, neuroimaging and neuropsychological studies have demonstrated that both enuresis and ADHD are related to a delay in central nervous system maturation. $^{32,33}$ However, genetic studies have shown that enuresis-related genes on chromosomes 8, 12, 13 and 22 are not associated with ADHD. ${ }^{34}$

ADHD may negatively impact drug compliance and the prognosis of enuresis, and one study reported a noncompliance rate of $48 \%$ in patients with coexisting ADHD. ${ }^{35}$ In addition, children with ADHD have been reported to be three times more likely to have persistent enuresis into adolescence or young adulthood. ${ }^{13}$ Effective ADHD medications such as methylphenidate, ${ }^{36}$ tricyclic antidepressants, and atomoxetine ${ }^{37}$ have been reported to be effective for enuresis. In contrast, drugs used for the treatment of coexisting psychiatric disorders in patients with ADHD such as second-generation antipsychotic drugs may cause enuresis. ${ }^{38}$ Coexisting psychiatric disorders should be taken into consideration during the assessment and treatment of children with both enuresis and ADHD. Moreover, clinicians should closely monitor the adherence to medications, their effects and any adverse events.

To the best of our knowledge, this is the first study with the largest sample size to provide evidence of the significant associations between enuresis and an extensive range of psychiatric disorders in children and adolescents in Taiwan over a 15-year study period. Most previous studies of the psychiatric problems associated with enuresis have been based on questionnaires and parent- or teacher-reported behavioral problems, leading to the possibility of over- or under-estimation of the psychiatric problems. The use of a nationwide population-based database of health care in our study avoided selection bias when recruiting the study subjects and avoided recall bias when filling out questionnaires. In addition, the diagnoses of enuresis and psychiatric disorders in this study were validated in medical evaluations by board-certified physicians and psychiatrists, resulting in better diagnostic validity. Nevertheless, there are several limitations related to the LHID 2010 database. First, it lacks information on annual household income, parental education, and family history of enuresis, which are known risk factors for enuresis. Second, the diagnoses of enuresis and psychiatric disorders were dependent on ICD codes used in the NHIRD database, and so children with enuresis who did not seek professional help for either enuresis, ADHD or another psychiatric disorder may have resulted in underestimation of the prevalence of enuresis or psychiatric disorders. Third, the exact proportions of day wetters only, day and night wetters, and nocturnal enuretics only were not available in our enuretic cohort as the definition of enuresis has been revised over the past years, and varied definitions of enuresis are used by different specialists. The enuretic cohort therefore potentially included some day wetters only or day and night wetters which may have impacted the prevalence of comorbidities of psychiatric disorders. ${ }^{39}$

\section{Conclusions}

Based on the results of the current and previous studies, children with enuresis have an increased rate of psychiatric disorders, with ADHD being the most prevalent. Further studies are needed to elucidate the mechanisms between 
the high rate of the coexistence of enuresis and psychiatric disorders. The results of this study may provide important implications for therapeutic interventions for children with enuresis. Clinicians should routinely screen for the coexistence of enuresis and psycho-behavioral disorders and vice versa. Therapy should be individualized based on the presence of comorbidities to ensure optimal outcomes.

\section{Abbreviations}

ADHD, attention-deficit/hyperactivity disorder; ASD, autism spectrum disorder; CD, conduct disorder; CI, confidence interval; DBD, disruptive behavior disorders; ICD-9-CM, International Classification of Diseases, Ninth Revision, Clinical Modification; LHID 2010, Longitudinal Health Insurance Database 2010; MDD, major depressive/dysthymic disorder; NHI, National Health Insurance; NHIRD, National Health Insurance Research Database; ODD, oppositional defiant disorder; OR, odds ratio.

\section{Acknowledgment}

This study was supported by a grant from Taipei Veterans General Hospital (V105C-126) in Taiwan.

\section{Author Contributions}

All authors contributed to data analysis, drafting and revising the article, gave final approval of the version to be published, and agree to be accountable for all aspects of the work.

\section{Disclosure}

The authors report no conflicts of interest in this work.

\section{References}

1. von Gontard A. Elimination disorders: a critical comment on DSM-5 proposals. Eur Child Adolesc Psychiatry. 2011;20(2):83-88. doi:10. 1007/s00787-010-0152-2

2. Nevéus T, von Gontard A, Hoebeke P, et al. The standardization of terminology of lower urinary tract function in children and adolescents: report from the Standardization Committee of the International Children's Continence Society. J Urol. 2006;176(1):314-324. doi:10.1016/S0022-5347(06)00305-3

3. Chang P, Chen WJ, Tsai WY, Chiu YN. An epidemiological study of nocturnal enuresis in Taiwanese children. BJU Int. 2001;87:678-681. doi:10.1046/j.1464-410x.2001.02161.x

4. Hansakunachai T, Ruangdaraganon N, Udomsubpayakul U, Sombuntham T, Kotchabhakdi N. Epidemiology of enuresis among school-age children in Thailand. J Dev Behav Pediatr. 2005;26 (5):356-360. doi:10.1097/00004703-200510000-00003

5. Bower WF, Moore KH, Shepherd RB, Adams RD. The epidemiology of childhood enuresis in Australia. Br J Urol. 1996;78:602-606. doi:10.1046/j.1464-410X.1996.13618.x
6. Etuk IS, Ikpeme O, Essiet GA. Nocturnal enuresis and its treatment among primary school children in Calabar Nigeria. Niger J Paediatr. 2011;38(2):78-81. doi:10.4314/njp.v38i2.72248

7. Schlomer B, Rodriguez E, Weiss D, Copp H. Parental beliefs about nocturnal enuresis causes, treatments, and the need to seek professional medical care. J Pediatr Urol. 2013;9(6 Pt B):1043-1048. doi:10.1016/j.jpurol.2013.02.013

8. Shreeram S, He JP, Kalaydjian A, Brothers S, Merikangas KR. Prevalence of enuresis and its association with attention-deficit/ hyperactivity disorder among U.S. children: results from a nationally representative study. $J$ Am Acad Child Adolesc Psychiatry. 2009;48(1):35-41. doi:10.1097/CHI.0b013e318190045c

9. Baeyens D, Roeyers H, Van Erdeghem S, Hoebeke P, Vande Walle J. The prevalence of attention deficit-hyperactivity disorder in children with nonmonosymptomatic nocturnal enuresis: a 4-year follow up study. J Urol. 2007;178(6):2616-2620. doi:10.1016/j.juro.2007.07.059

10. Baeyens D, Roeyers H, D'Haese L, Pieters F, Hoebeke P, Vande Walle J. The prevalence of ADHD in children with enuresis: comparison between a tertiary and non-tertiary care sample. Acta Paediatr. 2006;95(3):347-352. doi:10.1080/08035250500434736

11. Steinhausen HC, Göbel D. Enuresis in child psychiatric clinic patients. J Am Acad Child Adolesc Psychiatry. 1989;28(2):279-281. doi:10.1097/00004583-198903000-00022

12. Amiri S, Shafiee-Kandjani AR, Naghinezhad R, Farhang S, Abdi S. Comorbid psychiatric disorders in children and adolescents with nocturnal enuresis. Urol J. 2017;14(1):2968-2972.

13. Baeyens D, Roeyers H, Demeyere I, Verté S, Hoebeke P, Vande Walle J. Attention-deficit/hyperactivity disorder (ADHD) as a risk factor for persistent nocturnal enuresis in children: a two-year follow-up study. Acta Paediatr. 2005;94(11):1619-1625. doi:10.10 80/08035250510041240

14. Ghanizadeh A. Comorbidity of enuresis in children with attention-deficit/hyperactivity disorder. J Atten Disord. 2010;13 (5):464-467. doi:10.1177/1087054709332411

15. Joinson C, Heron J, Emond A, Butler R. Psychological problems in children with bedwetting and combined (day and night) wetting: A UK population-based study. J Pediatr Psychol. 2007;32(5):6 05-616. doi:10.1093/jpepsy/js1039

16. Weaver A, Himle JA, Taylor RJ, Matusko NN, Abelson JM. Urban vs rural residence and the prevalence of depression and mood disorder among African American women and non-Hispanic white women. JAMA Psychiatry. 2015;72(6):576-583. doi:10.1001/jamapsychiatry. 2015.10

17. Liu CY, Hung YT, Chuang YL, et al. Incorporating development stratification of Taiwan townships into sampling design of large scale health interview survey. J Health Manag. 2006;4:1-22.

18. Gulisano M, Domini C, Capelli M, Pellico A, Rizzo R. Importance of neuropsychiatric evaluation in children with primary monosymptomatic enuresis. J Pediatr Urol. 2017;13(1):36.e1-36.

19. Byrd RS, Weitzman M, Lanphear NE, Auinger P. Bed-wetting in US children: epidemiology and related behavior problems. Pediatrics. 1996;98:414-419.

20. von Gontard A, Moritz AM, Thome-Granz S, Freitag C. Association of attention deficit and elimination disorders at school entry: a population based study. J Urol. 2011;186(5):2027-2032. doi:10. 1016/j.juro.2011.07.030

21. Amiri S, Shafiee-Kandjani AR, Fakhari A, et al. Psychiatric comorbidities in ADHD children: an Iranian study among primary school students. Arch Iran Med. 2013;16(9):513-517. doi:10.13169/AIM.006

22. Mellon MW, Natchev BE, Katusic SK, et al. Incidence of enuresis and encopresis among children with attention-deficit/hyperactivity disorder in a population-based birth cohort. Acad Pediatr. 2013;13 (4):322-327. doi:10.1016/j.acap.2013.02.008

23. Biederman J, Santangelo SL, Faraone SV, et al. Clinical correlates of enuresis in ADHD and non-ADHD children. $J$ Child Psychol Psychiatry. 1995;36(5):865-877. doi:10.1111/jcpp.1995.36.issue-5 
24. Yousefichaijan P, Khosrobeigi A, Salehi B, et al. Incidence of obsessive-compulsive disorder in children with nonmonosymptomatic primary nocturnal enuresis. J Pediatr Neuosci. 2016;11 (3):197-199. doi:10.4103/1817-1745.193371

25. Hyde TM, Deep-Soboslay A, Iglesias B, et al. Enuresis as premorbid developmental marker of schizophrenia. Brain. 2008;131(Pt 9):24 89-2498. doi:10.1093/brain/awn167

26. Comings DE, Comings BG. A controlled study of Tourette syndrome. VI. Early development, sleep problems, allergies, and handedness. Am J Hum Genet. 1987;41:822-838.

27. von Gontard A, Pirrung M, Niemczyk J, Equit M. Incontinence in children with autism spectrum disorder. J Pediatr Urol. 2015;11 (5):264.e1-7. doi:10.1016/j.jpurol.2015.04.015

28. Park JH, Bang YR, Kim CK. Sex and age differences in psychiatric disorders among children and adolescents: high-risk students study. Psychiatry Investig. 2014;11(3):251-257. doi:10.4306/pi.2014.11.3. 251

29. Quintero J. Enuresis and attention deficit hyperactivity disorder (ADHD) in children and adolescents. Clinics Mother Child Health. 2014;11:160

30. Arnell $\mathrm{H}$, Hjälmås $\mathrm{K}$, Jägervall $\mathrm{M}$, et al. The genetics of primary nocturnal enuresis: inheritance and suggestion of a second major gene on chromo-some 12q. J Med Genet. 1997;34:360-365. doi:10.1136/ jmg.34.5.360

31. Thapar A, Cooper M. Attention deficit hyperactivity disorder. Lancet. 2016;387(10024):1240-1250. doi:10.1016/S0140-6736(15) 00238-X

32. Fernández A, Quintero J, Hornero R, et al. Complexity analysis of spontaneous brain activity in attention-deficit/hyperactivity disorder diagnosticimplications. Biol Psychiatry. 2009;65(7):571-577. doi:10. 1016/j.biopsych.2008.10.046
33. Lei D, Ma J, Shen X, et al. Changes in the Brain Microstructure of Children with Primary Monosymptomatic Nocturnal Enuresis: A Diffusion Tensor Imaging Study. PLoS One. 2012;7(2):e31023. doi:10.1371/journal.pone.0031023

34. Elia J, Takeda T, Deberardinis R, et al. Nocturnal enuresis: a suggestive endophenotype marker for a subgroup of inattentive attention-deficit/hyperactivity disorder. $J$ Pediatr. 2009;155 (2):239-244. doi:10.1016/j.jpeds.2009.02.031

35. Crimmins CR, Rathburn SR, Husman DA. Management of urinary incontinence and nocturnal enuresis in attention-deficit hyperactivity disorder. J Urol. 2003;170(4 Pt 1):1347-1350. doi:10.1097/01. ju.0000084669.59166.16

36. Bahali K, Ipek H, Uneri OS. Methylphenidate and atomoxetine for treatment of nocturnal enuresis in a child with attention-deficit hyperactivity disorder. Eur Child Adolesc Psychiatry. 2013;22 (10):649-650. doi:10.1007/s00787-013-0414-x

37. Sumner CR, Schuh KJ, Sutton VK, Lipetz R, Kelsey DK. Placebocontrolled study of the effects of atomoxetine on bladder control in children with nocturnal enuresis. J Child Adolesc Psychopharmacol. 2006;16(6):699-711. doi:10.1089/cap.2006.16.699

38. Barnes TR, Drake MJ, Paton C. Nocturnal enuresis with antipsychotic medication. Br J Psychiatry. 2012;200(1):7-9. doi:10.1192/bjp. bp. 111.095737

39. von Gontard A, Mauer-Mucke K, Plück J, Berner W, Lehmkuhl G. Clinical behavioral problems in day- and night-wetting children Pediatr Nephrol. 1999;13(8):662-667. doi:10.1007/s004670050677
Clinical Epidemiology

\section{Publish your work in this journal}

Clinical Epidemiology is an international, peer-reviewed, open access, online journal focusing on disease and drug epidemiology, identification of risk factors and screening procedures to develop optimal preventative initiatives and programs. Specific topics include: diagnosis, prognosis, treatment, screening, prevention, risk factor modification,

Submit your manuscript here: https://www.dovepress.com/clinical-epidemiology-journal

\section{Dovepress}

systematic reviews, risk \& safety of medical interventions, epidemiology \& biostatistical methods, and evaluation of guidelines, translational medicine, health policies \& economic evaluations. The manuscript management system is completely online and includes a very quick and fair peer-review system, which is all easy to use. 